\title{
Missed US nomination leaves climate post up for grabs
}

\section{Jim Giles, Washington}

The future leadership of the Intergovernmental Panel on Climate Change is up in the air this week, after the United States failed to renominate Robert Watson, the panel's current chair.

Watson's six-year term as chair of the panel, which was set up by the United Nations in 1988 to establish an international consensus on climate-change research, ends this year. The panel's Geneva-based secretariat had asked member nations to put forward their nominations for the position by 15 March.

India's nomination of Rajendra Pachauri, director of the Tata Energy Research Institute in New Delhi and current vice-chair of the panel, was the only one to arrive by the deadline, secretariat officials say. Pachauri is a former adviser to the World Bank and a director of the Indian Oil Corporation.

Watson, an ecologist who is chief scientist at the World Bank, says that he would be willing to serve a second term as chair and that he still hopes the United States will support his re-election. Watson was nominated by the United States when he was elected in 1996, but observers say that his former role as associate director for environment at the White House Office of Science and Technology Policy under President Bill Clinton, and his closeness to environmental advocacy groups, may dissuade the Bush administration from nominating him this time round.

Renate Christ, deputy secretary of the secretariat, says that there is no clear procedure for how nominations should be made, and that the secretariat may continue to accept nominations up until the election of the chair in April. She also points out that Bert Bolin, the Swedish meteorologist who preceded Watson as chair, was re-elected for his second term without being renominated.

The panel's governing body will vote on the position when it meets in Geneva in April. It is unclear how member states would vote if both Watson and Pachauri stand. Christ says that several countries have expressed a desire for Watson to stay on. But some nations may feel that it is time for a representative of a developing nation to head the panel.

Whoever is elected will have to oversee the panel's fourth climate-change assessment, which is due to be completed over the next five to seven years.

www.jpcc.ch
Breast-cancer survey sets screening age for women

Helen Pearson, London

The World Health Organization (WHO)

has added its voice to the heated debate over when women should start having mammograms.

The International Agency for Research on Cancer (IARC) - part of WHO convened a panel of 24 scientists this month to review the available evidence for the health benefits of mammography. Chaired by Bruce Armstrong of the University of Sydney, the panel concluded that women aged 50 and over benefit from breast-cancer screening using mammograms.

But it fell short of endorsing the recommendation made last month by the US health department that women over 40 should have regular mammograms (see Nature 415, 950; 2002).

Some researchers still question whether the total number of lives saved by screening outweigh those lost as a result of treatment - even in older women.

But the IARC hopes that its final report, to be published within three months, will help to inform policy-makers around the world who are implementing or refining screening programmes.

\section{Cash shortfall means time out for physicists}

\section{Geoff Brumfiel, Washington}

Nuclear physicists in the United States have a synchronization problem. Just as muchwanted operating time is becoming available on major facilities, the physics division of the National Science Foundation (NSF) is running out of cash to support the researchers who want to use the equipment.

This year, the funds available to the physics division for supporting primary investigator grants have fallen by $11.5 \%$ compared with 2001. Given that most of the money is already committed to grants lasting several years, this translates into a cut of one-third in the number of new grants to be awarded in the next couple of months.

Nuclear physicists claim that they will be hit especially hard, because they will miss a rare opportunity to run their best facilities at close to full capacity. Earlier this year, the Department of Energy proudly announced that the United States' two largest facilities for nuclear science - the Relativistic Heavy Ion Collider at Brookhaven National Laboratory in New York state and the Continuous Electron Beam Accelerator
Facility at the Thomas Jefferson National Accelerator Facility in Newport News, Virginia - will have their operating times substantially increased next year.

The NSF's physics division will receive a $4 \%$ budget increase this year. But because of its obligations to run its own facilities in Michigan, Louisiana and Washington state, and its increased grants to larger physics groups, the division is facing a sharp cut in the number of individual researchers it can support. "It's a difficult situation," concedes Joseph Dehmer, the division's director.

"It's going to have a very, very unfortunate effect," says Lawrence Cardman, associate director of physics at the Jefferson lab. Cardman says that over a quarter of the lab's staff are funded by the NSF, and many will lose their grants this year. He fears that young scientists will be forced to abandon nuclear physics as a result.

"This is a disastrous situation," says Baha Balantekin of the University of Wisconsin in Madison. Most graduate students are supported by primary investigator grants, he says, and nuclear physics is already running

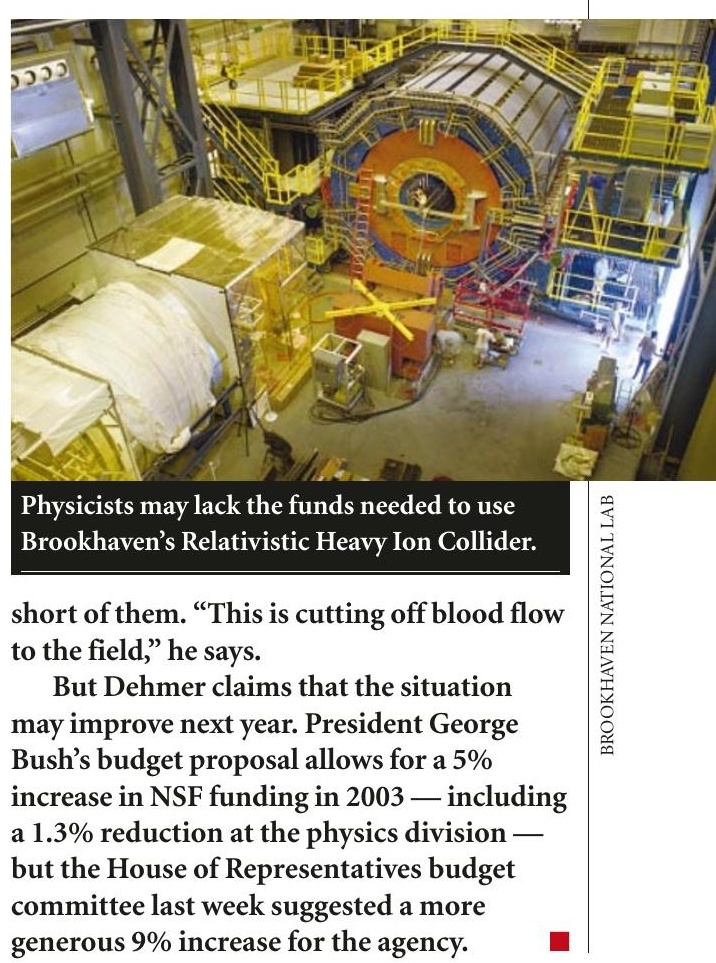
generous $9 \%$ increase for the agency. 